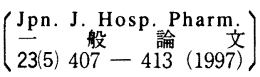

\title{
The Effect of Dried Aluminum Hydroxide Gel on the Blood Concentration of Cyclosporine-A
}

\author{
MASAYUKI ICHISAWA $\uparrow^{1}$, ICHIRO OHTA $\dagger^{1}$, RYOKO SUZUKI $\dagger^{1}$, YOSHITERU \\ WATANABE $\dagger^{2}$, MASANORI IWATA $\dagger^{1}$, SHUSUKE MATSUYAMA $\dagger^{3}$, \\ MITSUO MATSUMOTO ${ }^{2}$ and SHOICHI SHIROTAKE $\dagger^{1}$ \\ Department of Pharmacy, Yokohama City University Hospital $\dagger^{1}$ \\ Department of Pharmaceutics, Showa College of Pharmaceutical Sciences $\dagger^{2}$ \\ Department of Pediatrics, Yokohama City University School of Medicine $\dagger^{3}$
}

$\left(\begin{array}{l}\text { Received July 16, } 1997 \\ \text { Accepted September 3, } 1997\end{array}\right)$

\begin{abstract}
The blood concentrations of cyclosporine-A (CyA) decreased remarkably in a pediatric patient who had been administered CyA combined with dried aluminum hydroxide gel (DALG). The difference in the ratio of the dosage per body weight to the blood concentrations of CyA was remarkable in patients who underwent CyA immunosuppressive therapy either with DALG $(n=25)$ or without DALG $(\mathrm{n}=21)$. The ratio was $15.6 \pm 8.9$ (mean \pm standard deviation) in patients with DALG and $25.9 \pm 15.4$ in those without DALG. After adding DALG to an in vitro $\mathrm{pH} 1.2 \mathrm{CyA}$ solution, the solution became turbid and the concentration of CyA in the supernatant decreased by about 20 percent compared to the control without DALG. In rats, the area under the curve (AUC) of CyA with DALG was 17 percent lower than that of CyA alone. These findings indicate that the blood concentrations of CyA are affected by administration with DALG, and that aluminum hydroxide gel decreases the absorption of CyA by adsorption or complex formation.
\end{abstract}

Key words — cyclosporine A, pediatrics, dried aluminum hydroxide gel, drug interaction

\section{Introduction}

Cyclosporine-A (CyA), selectively inhibits the T-lymphocytes is a powerful immnunosuppressant drug. Now, CyA is widely used in organ transplantation ${ }^{1,2)}$, bone marrow transplantation ${ }^{3)}$, and in the treatment of such autoimmune diseases as psoriasis ${ }^{4)}$, rheumatoid arthritis ${ }^{5)}$. It is reported that the therapeutic effect and toxicity of CyA are related to the blood concentrations of $\mathrm{CyA}^{6)}$. CyA treatment must thus be closely monitored due to its wide interpatient and intrapatient pharmacokinetic variability ${ }^{7}$. However, it is not clear on the point. So it is necessary to study the pharmacokinetics of CyA and to exclude the labile factors for the optimal use of this drug in clinical practice. The one of those factors is drug interaction.

The main mechanism of the interaction is included to inhibit the hepatic metabolism of CyA by blocking the cytochrome $\mathrm{p}-450$ system $^{8,9)}$ or to induce of the metabolic enzymes ${ }^{10,11)}$. The effects of

$\dagger^{113)}$ 横浜市金沢区福浦3-9;3-9, Fukuura, Kanazawa-ku, Yokohama-shi, Kanagawa, 236 Japan

$t^{2)}$ 東京都町田市東玉川学園3-3165; 3-3165, Higashi-tamagawagakuen, Machida-shi, Tokyo, 194 Japan 
other drugs on metabolic enzymes have previously been studied in many drugs. On the other hand, there has so far been no report that the absorption of CyA was affected by the concurrent administration of drugs in the gastrointestinal tract, although there has been a report which showed that the hyperactivity of the gastrointestinal tract affects the absorption of $\mathrm{CyA}^{12)}$.

We experienced a case in which the blood concentration of CyA decreased remarkably in a pediatric patient administered CyA with dried aluminum hydroxide gel (DALG). There has been no previous report on the interaction between the blood concentration of CyA and DALG. We therefore investigated the effect of DALG on CyA therapy.

\section{Patients and Methods}

\section{A Case and Subjects}

The patient, who inspired this study, was an 8-month-old boy (W.R) who had been hospitalized with Langerhans cell histiocytosis ( $\mathrm{LCH})$ and had thus been administered CyA. He began to show eczema mainly on his face at one month of age, and thereafter he demonstrated a generalized rash ; he was diagnosed to have LCH by a skin biopsy. As a result, he was soon admitted to our hospital. At first, he was began with immunosuppressive therapy by per oral prednisolone (PSL), and coadministered with DALG to prevent gastropathy by PSL. However, this therapy was not effective and thus other therapies were performed including etoposide (VP 16) and/or vinblastine sulfate (VLB). Unfortunately, these therapies were also unable to control his condition and he showed bone lesions by the activation of osteoclastic cells and internal organ damage by the infiltration of Langerhans cells (LC).

Accordingly, with his family's consent, CyA was administered orally and the blood concentrations of CyA were monitored. The drugs in combination with CyA, consisted of PSL, and DALG, while also including sulfamethoxazole-trimetoprim (ST), amphotericin B (AMPH) and polymyxin $\mathrm{B}$ sulfate (PLB) to protection against the influence because of bone marrow suppression.

To compare this patient with others, we selected seven subjects (from 3-14 year-old age, 11.5$58.0 \mathrm{~kg}$ weight) with no kidney or liver dysfunction and who had undergone the same CyA therapy as $\mathrm{W}$. R at the time of dosing and blood sampling.

Table 1. Characteristics of 7 Pediatric Patients

\begin{tabular}{ccccc}
\hline Patient No. & Disease & Age(yr) & Body weight(kg) & Dose(mg/kg) \\
\hline 1 & BMT & 6 & 18 & 6.86 \\
2 & BMT & 14 & 58 & $3.48-5.57$ \\
3 & BMT & 3 & 12 & 6.67 \\
4 & BMT & 8 & 25 & $2.88-3.20$ \\
5 & BMT & 8 & 22 & $4.60-9.20$ \\
6 & SAA & 14 & 43 & 4.65 \\
7 & SAA & 3 & 11.5 & $4.39-11.40$ \\
\hline mean & & 8 & 27.1 & $4.79-6.78$ \\
\hline
\end{tabular}

BMT:Bone Marrow Transplatation

SAA:Sever Aplastic Anemia

\section{Measurement method of CyA in the whole blood}

Blood samples were obtained at trough ; namely, the time immediately before the next dose was administered. Whole blood samples of about $2 \mathrm{ml}$ were collected into tubes containing EDTA $2 \mathrm{~K}$ 
anticoagulant. Whole blood concentrations of CyA were measured by high performance liquid chromatography (HPLC), with the partial improvement solid phase extraction method of Benet et al. ${ }^{13)}$, using internal standard cyclosporine $\mathrm{D}(\mathrm{CyD})$. Internal standard $\mathrm{CyD}$ was added to whole blood of $0.5 \mathrm{ml}$, mixed up and then was centrifuged for $10 \mathrm{~min}$ at $3500 \mathrm{rpm}$ (LC-121; TOMY SEIKO CO., LTD.). The supernate solution was passed through the ISOLUTE SPE CN (International Sorbent Technolgy LTD.) extraction column on the top of the Vac-Elut chamber, and washed with water of $50 \mathrm{ml}$ followed by $0.5 \mathrm{M}$ acetic acid of $2 \mathrm{ml}$, then columns were eluted with acetonitrile of $2 \mathrm{ml}$. The eluent was evaporated to dryness under nitrogen and the residue was reconstituted into mobile phase (70\% acetonitrile) of $250 \mu \mathrm{l}$, from which $100 \mu \mathrm{l}$ was injected into the HPLC system (LC-6 A ; SHIMAZU CO., LTD.). The HPLC conditions were as follows ; an Octadesil C18 (Develosil ODS-5 ; NOMURA CHEMICAL CO., LTD) column was used and maintained at $70^{\circ} \mathrm{C}$ in a column heater. The flow rate of the mobile phase was $1.3 \mathrm{ml} / \mathrm{min}$. The detector wavelength was set at $205 \mathrm{~nm}$. The CyA concentrations were calculated from the ratio of the peak heights for CyA to CyD with a standard curve. The HPLC measurements of CyA in the whole blood was immediately started after blood sampling, each sample was measured three times and the mean was considered to be the blood concentration of CyA.

\section{Mixing test of CyA and DALG}

One $\mathrm{ml}$ of oral CyA liquid (Sandimmun ${ }^{\circledR}$, Lot No. 5207) was added to the pH 1.2 solution consisting of up to $100 \mathrm{ml}$ of the 1st solution for Disintegration Test (Pharmacopoeia of Japan), and then was mixed. After centrifugal separation for $10 \mathrm{~min}$ at $3500 \mathrm{rpm}$ (LC-121; TOMY SEIKO CO., LTD.), it was diluted 100 times with $\mathrm{pH} 1.2$ solution (Dilution solution). The CyA contents in $0.5 \mathrm{ml}$ of the Dilution solution was in the range that observed in the whole blood experiment.

Next, 1 gram of DALG (Alumigel ${ }^{\circledR}$, Lot No. F 6 E 02) was added to the Dilution solution to make a quantity of $100 \mathrm{ml}$, and then was shaken up for 60 minutes in a $37^{\circ} \mathrm{C}$ water bath. While shaking, we sampled it with the passage of time and measured the CyA contents in the same way. Simultaneously, we also measured the CyA content using the 2nd solution (pH 6.8) for Disintegration Test.

\section{Influence of DALG on the blood concentration of CyA in rats}

Blood samples were obtained from indwelling canula at 30, 60, 90, 120, 180, 240, and 300 minutes after a single oral CyA liquid administration $(50 \mathrm{mg} / \mathrm{kg}$ ) to five Wistar series male rats (250.0$272.0 \mathrm{~g}$ weight). In another series of five Wistar rats (232.0-262.0 g weight) the blood was sampled and obtained in the same way, and after they were administered DALG (50 mg/kg/day) for 4 days, the blood concentrations of CyA were measured by HPLC.

\section{Statistical analysis}

Both parametric and nonparametric statistical methods were used. When the data were normally distributed, the two-sample $t$ test was used for statistical comparisons. When the data were nonnormally distributed, the Mann-Whitney test was used. A $P$ value of less than 0.05 was considered to be statistically significant.

\section{Results}

\section{Profile of CyA blood concentration in the case of $W . R$}

The patient (W. R) underwent several types of immunosuppressive therapy which were ineffec- 
tive. The progress of $\mathrm{LCH}$ and the adverse effects of immunosuppressive agents had induced bone marrow suppression. At the time of CyA administration, the patient's general condition was unsatisfactory. As Mahmoud et al. recommended in their report ${ }^{14)}$, CyA therapy was initiated twice a day in a dose of $12 \mathrm{mg} / \mathrm{kg} /$ day. Although CyA blood concentration measured five days after the initiation of the therapy was expected to be approximately $150-250 \mathrm{ng} / \mathrm{ml}$ at the trough (12 hours after CyA administration), the actual concentration was $90 \mathrm{ng} / \mathrm{ml}$. A gradual increase in CyA dosage showed the transient elevation of CyA blood concentration which improved various symptoms including osteolysis. The blood concentration of CyA, however, decreased in the course of time (Fig. 1 ). In the meantime the patient was given CyA constantly in combination with DALG.

The main data of clinical examinations and the drugs used for combination therapy are shown in Table 2 .

\section{Comparison of the ratios of CyA blood concentration/dosage in patients}

Figure 2 gives CyA dosages adopted and the blood concentrations measured in the eight children including W.R.

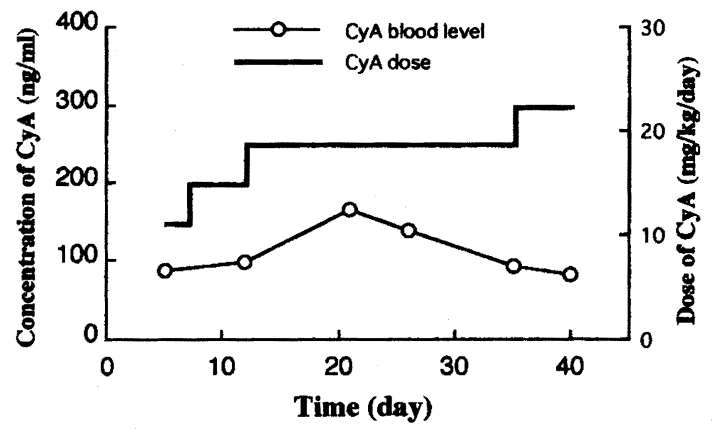

Fig. 1. Relationships between Dose and Blood Concentration of CyA in the Case of W. R

The concentration of CyA was trough level in steady state after oral administration.

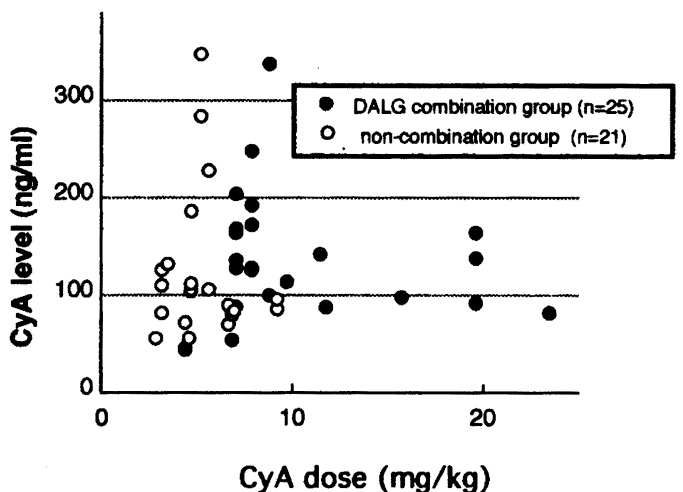

Fig. 2. Relationships between Dose and Trough Level of CyA in the Eight Subjects

Table 2. Drugs and Laboratory Values of Patient W.R at 5 Day after First CyA Administration

\begin{tabular}{|c|c|c|c|c|c|c|}
\hline \multicolumn{3}{|l|}{ Injection } & \multicolumn{4}{|c|}{ Oral } \\
\hline $\begin{array}{l}20 \% \text { albumin inj. } \\
\text { fluconazole inj. } \\
\text { furosemide inj. } \\
\text { VLB inj. }\end{array}$ & $\begin{array}{l}20 \mathrm{ml} / \text { day } \\
100 \mathrm{mg} / \text { day } \\
10 \mathrm{mg} / \text { day } \\
1 \mathrm{mg} / \text { week }\end{array}$ & & & $\begin{array}{l}\text { PSL } \\
\text { DALG } \\
\text { ST } \\
\text { AMPH } \\
\text { PLB } \\
\text { CyA }\end{array}$ & & $\begin{array}{l}15 \mathrm{mg} / \text { day } \\
0.5 \mathrm{~g} / \mathrm{day} \\
0.5 \mathrm{~g} / \mathrm{day} \\
400 \mathrm{mg} / \mathrm{day} \\
0.4 \mathrm{MU} / \mathrm{day} \\
150 \mathrm{mg} / \mathrm{day}\end{array}$ \\
\hline & Serum & $\mathrm{od} \mathrm{C}$ & ation & & & \\
\hline $\begin{array}{lc}\text { WBC } & \times 10^{3} / \mathrm{cmm} \\
\text { RBC } & \times 10^{4} / \mathrm{cmm} \\
\text { Hb } & \mathrm{g} / \mathrm{dl} \\
\text { PL } & \times 10^{3} / \mathrm{cmm}\end{array}$ & $\begin{array}{l}1.2 \\
291 \\
9.3 \\
2.2\end{array}$ & & & $\begin{array}{l}\text { CHE } \\
\text { GOT } \\
\text { GPT } \\
\text { LDH }\end{array}$ & $\begin{array}{c}\mathrm{mU} / \mathrm{ml} \\
\mathrm{mU} / \mathrm{ml} \\
\mathrm{mU} / \mathrm{ml} \\
\mathrm{mU} / \mathrm{ml}\end{array}$ & $\begin{array}{l}150 \\
7 \\
10 \\
299\end{array}$ \\
\hline & $\begin{array}{l}\text { ALB } \\
\text { CRP } \\
\text { BUN } \\
\text { Scr }\end{array}$ & $\begin{array}{c}\mathrm{g} / \mathrm{dl} \\
\mathrm{mg} / \mathrm{dl} \\
\mathrm{mg} / \mathrm{dl} \\
\mathrm{mo} / \mathrm{dl}\end{array}$ & $\begin{array}{l}3.0 \\
3.8 \\
15 \\
0.2\end{array}$ & & & \\
\hline
\end{tabular}


The subjects were divided into two groups; those who were placed on CyA therapy in combination with DALG on the day CyA blood concentration was to be measured $(n=25)$ and those who were placed on single CyA therapy $(n=21)$. The ratios of CyA blood concentration/dosage were $15.6 \pm 8.9$ (mean \pm S. D.) in the former group and $25.9 \pm 15.4$ in the latter group and the difference between two groups was significant $(\mathrm{P}<0.05)$. Therefore it was shown that the combination therapy with DALG reduced the blood concentration of CyA. W. R received DALG combination therapy throughout the six sessions of the measurement of CyA blood concentration. His ratio of blood concentration/dosage was $6.2 \pm 1.7$. Compared with other patients, W. R showed a more significant decrease in CyA blood concentration.

\section{Interaction between $C y A$ and $D A L G$ in vitro}

Oral CyA liquid was diluted with the 1st solution $(\mathrm{pH}$ 1.2) for Disintegration Test. This diluted solution was mixed with DALG and the content of CyA was measured. CyA content was $82.3 \pm$ $14.3 \%$ (mean \pm S. D.) immediately after mixing with DALG and $79.9 \pm 12.7 \%$ in 60 minutes later. These data reveal the significant decrease in CyA content $(\mathrm{P}<0.02)$. After being mixed with DALG, the mixture was left for 60 minutes. During this period the increase in the $\mathrm{pH}$ value from 1.2 to $4.0 \pm 0.2$ was observed. The mixture had appearance of a white cloudy liquid. In the next experiment using the 2nd solution ( $\mathrm{pH}$ 6.8) for Disintegration Test, CyA concentrations measured immediately after being mixed with DALG and 60 minutes later were $99.2 \pm 3.9 \%$ and $92.5 \pm$ $10.8 \%$ respectively. The change of CyA concentrations was negligible. During this period the $\mathrm{pH}$ value increased from 6.8 to $6.9 \pm 0.3$ and the mixed solution did not become clouded (Fig. 3 ).

\section{Influence of DALG on the blood concentration of CyA in rats}

In the animal experiment, the dosage of CyA was 10 times as high as that for human was adopted in the present study. The dosage of DALG was converted to that for human. In order to set an indwelling canula, the rats were not fed from the day before the initiation of CyA administration. Blood samples were collected from the animals. The maximum volume collected at each sampling was $1.5 \mathrm{ml}$ because of technical matters. Blood sampling should be completed within the

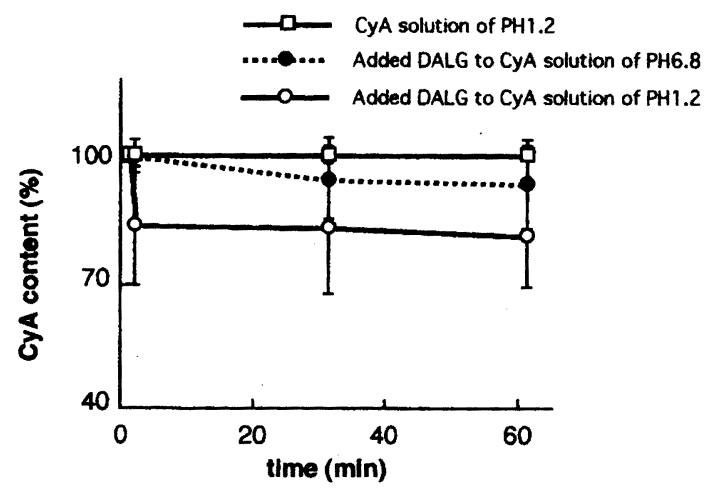

Fig. 3. Variation of CyA Content when DALG was Added to CyA Solution at $\mathrm{pH} 1.2$ or to that at $\mathrm{pH} 6.8$ at $37^{\circ} \mathrm{C}$

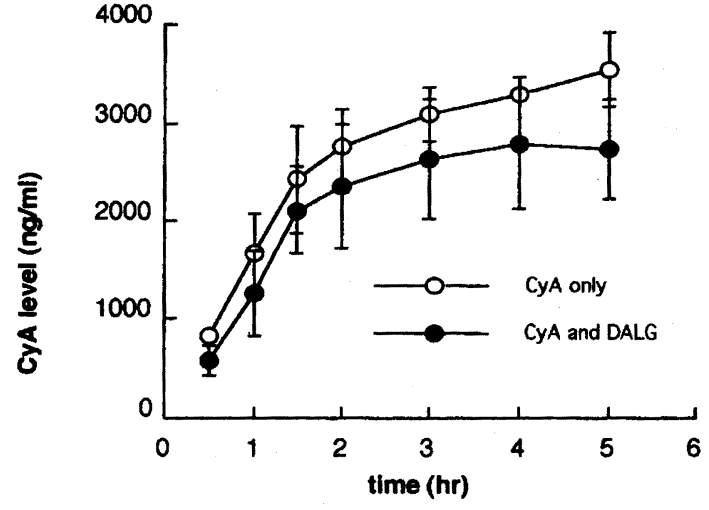

Fig. 4. Influence of DALG on the Blood Concentration of CyA in Rats

Blood concentration of CyA after a single oral CyA liquid administration $(50 \mathrm{mg} / \mathrm{kg})$ with or without DALG. 
five hours following CyA administration. The blood concentrations of CyA measured one hour after CyA administration were $1680 \pm 410 \mathrm{ng} / \mathrm{ml}$ in the control group and $1270 \pm 420 \mathrm{ng} / \mathrm{ml}$ in the group of DALG combination therapy. The blood concentrations measured five hours later were $3540 \pm 390 \mathrm{ng} / \mathrm{ml}$ in the control group and $2730 \pm 510 \mathrm{ng} / \mathrm{ml}$ in the combination group. The statistic difference, however, was not recognized because of the wide dispersion (Fig. 4 ).

\section{Discussion}

LCH is a disease resulting from the abnormal multiplication of Langerhans cells (LC). LC is regarded as one of the antigen presenting cells in the network of the immune system. Its activity and proliferation are regulated by cytokines ${ }^{15}$. Therefore the purpose of treatment for this disease is not the eradication of abnormal cells but the control of reactions. It is a well-known fact that the individual profile of the blood concentration of a drug is affected not only by the changes of histological functions occurring in the course of the disease ${ }^{16)}$ but also by the drugs used for combination therapy. Although W.R did not manifest abnormal digestive symptoms including diarrhea, he had already shown splenohepatomegaly and repeated rise of temperature before CyA administration. Furthermore the patient showed eruption and osteolysis of the frontal bone, which probably indicated the activation of LC. The laboratory tests revealed pancytopenia. There were suspicions of bone marrow suppression due to drug therapy using a nonspecific immunosuppressive agent and the aggravation of internal organ insufficiency. Low levels of serum cholinesterase and serum albumin suggested the dysfunction of liver parenchyma cells. CyA which flows into blood circulation is metabolized mainly in the liver. In the present case, CyA blood concentration had been expected to be high because of the impairment of metabolic enzyme synthesis due to hepatic dysfunction ${ }^{6,7)}$. The drug used for combination therapy included fluconazole and PSL, and were reported to influence CyA blood concentration. Fluconazole and PSL inhibit CyA metabolic enzymes and increase CyA blood concentration at the stages of metabolism ${ }^{17,18)}$. The blood concentration of CyA was low in the patient. This finding suggested the involvement of other factors which had no effect on stages of CyA metabolism.

The CyA blood concentration in seven patients (Fig.2) excluding W.R was measured when they were administered CyA with DALG or without DALG. The ratio of CyA blood concentration/dosage was $18.5 \pm 8$ in the combination group. This ratio exceeded the average ratio of the eight patients including W.R (15.6 \pm 8.9$)$. But, the ratio was $25.9 \pm 15.4$ in the noncombination group. These results indicated that CyA blood concentration was affected by DALG. CyA is mainly absorbed in the small intestine. The average bioavailability was reported to be $30 \%(5-70 \%)^{19)}$, and the absorption was affected by the secretion of bile acid $^{20)}$. These seven patients, however, showed no liver dysfunction. Aluminum salts can bind other drugs in the stomach, reducing the rate and extent of absorption of antibacterials such as erythromycin, ciprofloxacin, isoniazid, norfloxacin, ofloxacin, rifampicin, and most tetracycline, and other drugs such as phenytoin, itraconazole, ketoconazole, chloroquine, hydroxychloroquine, phenothiazines, iron, and penicillamine ${ }^{21}$. The interaction between DALG and CyA has not been mentioned in any reports so far. According to the package insert of DALG, because DALG dissolves in dilute hydrochloric acid, it forms a jelly when orally administered. The gelatinous film is acid insoluble and protects the ulcer surface. Because a wide area can be covered with this adsorption film for a long period of time, there existed 
the possibility that the administration of DALG affected the absorption of the drugs concomitantly used. Aluminum hydroxide neutralizes hydrochloric acid and also binds it adsorptively. The effect of DALG was observed also in the present in vitro experiment. DALG was added to the solution having the $\mathrm{pH}$ value of 1.2 at $37^{\circ} \mathrm{C}$, and the appearance of the mixed solution became cloudy in the course of time. The CyA content in the supernatant was decreased, probably by CyA clathration with the DALG gelatinous film. The decrease in CyA blood concentration was attributed to the apparent change induced by the above mentioned phenomenon.

In order to confirm the CyA interaction with DALG, an animal experiment using rats was performed. The area under the curve (AUC) of CyA in the combination group with DALG was lower than in the CyA single administration group [10.5 \pm 3.2 vs. $12.7 \pm 1.2 \mu \mathrm{g} \cdot \mathrm{hr} / \mathrm{L}$ (mean $\pm \mathrm{S}$. D.)]. However, the measurment results obtained for the first five hours demonstrated no statistically significant differences in AUC. The results of the in vivo experiment were in close agreement with those of the in vitro experiment (82.7\%).

The authors first recognized that CyA oral treatment in combination with DALG reduced approximately $20 \%$ of CyA blood concentration. Further work is urgently needed before the detailed action mechanism can be clarified. However, the present study definitely pointed out the fact that the formation of the DALG insoluble gelatinous film and its clathration affected CyA absorption.

\section{References}

1) R.Y.Calne, K.Rolles, D.J.G.White, S.Thiru, D.B.Evans, P.McMaster, D.C.Dunn, G.N.Craddock, R.G. Henderson, S.Aziz and P.Lewis, Lancet, 17, 1033-1036 (1979).

2) The Canadian Multicentre Transplant Study Group, N.Engl. J.Med., 309, 809-815 (1983).

3) R.L.Powles, B.Evans, C.Poole, A.Pedrazzini, M.Crofts, C.Pollard and G.Hughes, Transplant. Proc., 15, 2624-2627 (1983).

4) C.N.Ellis, U.S.Fradin, T.A.Hamilton and J.J.Voorhees, Arch. Dermatol, 131, 791-795 (1995).

5) P.Tugwell, C.Bombardier, M.Gent, K.J.Bennett, W.G.Bensen, S.Carette, A.Chalmers, J.M.Esdaile, A. V.Klinkhoff, G.R.Kraag, D.Ludwin and R.S.Roberts, Lancet, 335, 1051-1055 (1990).

6) B.D.Kahan, Tansplantation, 40, 457-476 (1985).

7) R.J.Ptachcinski, R.Venkataramanan and G.J.Burckart, Clin. Pharmacokinet., 11, 107-132 (1986).

8) J.T.C.Kwan, P.J.D.Foxall, D.G.C.Davidson, M.R.Bending and A.J.Eisinger, Lancet, 1, 282 (1987).

9) J.M.Pochet and Y.Pirson, Lancet, 26, 979 (1986).

10) R.A.Coward, A.T.Raftery and C.B.Brown, Lancet, 8, 1342-1343 (1985).

11) H.Carstensen, N.Jacobsen and H.Dieperink, Br.J. Clin. Phamacol., 21, 550-552 (1986).

12) N.K.Wadhwa, T.J.Schroeder, E.O'Flaherty, A.J.Pesce, S.A.Myre and M.R.First, Transplantation, 43, 211-213 (1987).

13) S.K.Gupta and L.Z.Benet, J. Liq. Chromatogr., 12, 1451-1462 (1989).

14) H.H.Mahmoud, W.C.Wang, and S.B.Murphy, Blood, 77, 721-725 (1991).

15) J.McLelland, V.Broadbent, E.Yeomans, M.Malone and J.Pritchard, Arch. Dis. Child., 65, 301-303 (1990).

16) J.Grevel, Transplant. Proc., 18 (suppl 5), 9-15 (1986).

17) G.C.Yee and T.R.McGuire, Clin. Pharmacokinet., 19, 319-332 (1990).

18) G.C.Yee and T.R.McGuire, Clin. Pharmacokinet., 19, 400-415 (1990).

19) J.Drewe, C.Beglinger and T.Kissel, Br. J. Clin. Pharmacol., 33, 39-43 (1992).

20) R.F.Quijano, N.Ohnishi and K.Umeda, Drug Metab. Dispos., 21, 141-143 (1993).

21) J.M.Ritter, L.D.Lewis and T.G.K.Mant,“A Textbook of Clinical Pharmacology", 3rd Ed., by Edward Arnold, Inc., London, 1995, pp. 398-399. 